\title{
EL DEBATE FILOSÓFICO ENTRE LA MODERNIDAD Y LA POSTMODERNIDAD DESDE UNA ÓPTICA FEMINISTA
}

\author{
Ana Isabel Hernández Rodríguez* \\ Elisa J. Pérez Rosales** \\ Universidad de La Laguna
}

\section{RESUMEN}

Este artículo analiza los paradigmas filosóficos de la modernidad y la postmodernidad con el fin de proponerlos como marcos conceptuales desde donde explicar el debate intrafeminista entre la igualdad y la diferencia. La aparición, a mediados y finales del siglo $\mathrm{xx}$, de la heterogeneidad feminista constituye una respuesta crítica a la noción moderna de universalidad en tanto mediada por sesgos androcéntricos. Finalmente, se pretende que el feminismo por el que apuesta Judith Butler puede ser interpretado como portador de una filosofía a caballo entre los paradigmas moderno y postmoderno de pensamiento, esto es, como una propuesta transmoderna.

Palabras clave: igualdad, diferencia, feminismo, modernidad, postmodernidad.

THE PHILOSOPHICAL DISCUSSION BETWEEN MODERNITY

AND POSTMODERNITY FROM A FEMINIST PERSPECTIVE

\section{Abstract}

This paper analyzes the philosophical paradigms of modernity and postmodernity with the aim to propose them as a conceptual basis to explain the intrafeminist discussion about equality and difference. The appearance, in the mid-to-end xx century, of the feminist heterogeneity supposed a critical response to the notion of universality meddled with androcentric bias. Finally, it is proposed that the feminism of Judith Butler may be interpreted as the bearer of a philosophy in-between modern and postmodern thinking, as a transmodern proposal.

KEYWORDS: equality, difference, feminism, modernity, postmodernity. 


\section{INTRODUCCIÓN}

A pesar de haber sido declarado muchas veces como obsoleto y estéril teóricamente, el debate intrafeminista entre la igualdad y la diferencia se ha (re)actualizado mediante los términos consenso y disenso, mismidad y otredad, y diferencia sexual y teorías del género. Además de estas versiones, la polémica entre el universalismo y el particularismo destaca por su interdisciplinariedad dentro la complejidad de la filosofía contemporánea. El debate feminista entre la igualdad y la diferencia es comprensible como una disputa desarrollada dentro de las tensiones argumentativas entre la modernidad y la postmodernidad.

La tendencia universalista del feminismo de la igualdad es también denominada humanista o unitarista y, a partir de la afirmación de los valores proclamados en la Ilustración ${ }^{1}$, cuestiona y denuncia la condena de las mujeres a la fisicalidad (Sabsay 123). Puesto que, en este feminismo, la vindicación es programática, la igualdad que se reclama tiene pretensiones de universalidad (AmORós 71).

Por otro lado, la tendencia particularista de los feminismos de la diferencia considera que cada sexo desarrolla su propia relación con el mundo: una manera de pensar, de sentir y de actuar de las mujeres que se debe reconocer y defender como propia. Esto se traduce en una afirmación de otro mundo que, fundado en lo femenino, se caracteriza allende los elementos masculinos y por no ser reducible a lo uno. Este clima de creciente complejidad y heterogénea problematización feminista provoca, asimismo, que la teoría feminista reflexione sobre sí misma y genere su propio amadrinamiento por parte de las revelaciones de las otras mujeres que, pertenecientes a otras y diferentes etnias, culturas y sexualidades, se consideraban marginales ${ }^{2}$. Son estas tensiones, este escenario de lo que podría llamarse la eclosión de la diferencia, el lugar compartido de donde surge la fecunda y polémica obra de Judith Butler. Una obra que, desde sus inicios, se ubica en una posición espaciotemporal a medio camino entre algunas vertientes de pensamiento postmodernas y las derivas feministas de mediados y finales del siglo pasado: una obra que, considerada en conjunto pero sin caer en sistematizaciones, logra articular una teoría que podría ser calificada de transmoderna. Y es que abre una tercera vía frente a los debates dicotómicos típicos de la disputa igualdad y diferencia recién nombrada.

* Email: ana.isabel.her.rod@gmail.com.

** Email: eliperezrosa@hotmail.com. blicano.

1 Valores que posibilitaron la Revolución francesa dadas sus referencias al laicismo repu-

2 Para ahondar en este análisis, véase Romero Morales, Yasmina (2017): «La otredad femenina en la narrativa colonial escrita por mujeres: Spivak y los feminismos postcoloniales». En: Cuestiones de género: de la igualdad y la diferencia, n. ${ }^{\circ}$ 12, pp. 39-53. 


\section{DE LA MODERNIDAD A LA POSTMODERNIDAD}

Tres son las fechas nucleares que pueden proponerse a la hora de exponer el marco vital y de pensamiento barroco, germen de lo que se denomina modernidad: 1632, 1637 y 1648. En el campo de la ciencia o, más concretamente, de la revolución científica que conlleva la preeminencia de la matematización y la experimentación de la naturaleza, el Diálogo sobre los dos máximos sistemas del mundo: ptolemaico y copernicano (1632) de Galileo Galilei sustituye y deja atrás el imaginario físico aristotélico y su forma de entender el mundo. A nivel social y cultural, el acontecimiento en que podría ubicarse el comienzo de la forma de vivir moderna es la Paz de Westfalia (1648), que pone fin a las convulsiones religiosas inaugurando gran parte del núcleo vital del Renacimiento. Y el Discurso del método (1637) de René Descartes, que abre con su "pienso, luego existo" la época moderna en filosofía.

Ahora bien, si este tan socorrido pienso, luego existo se establece durante más de tres siglos como lema de Occidente y se convierte en lo que da cuenta de la existencia humana a través del pensamiento y la razón, el siglo $\mathrm{xx}$ da un vuelco, con resonancias existencialistas, al precepto cartesiano. Surge, así, el existo, luego pienso de José Ortega y Gasset en su Qué es filosofía (1957): «Si existo yo que pienso, existe el mundo que pienso. Por tanto, la verdad radical es la coexistencia de mí con el mundo. Existir es primordialmente coexistir - es ver yo algo que no soy yo, amar yo a otro ser, sufrir yo de las cosas» (122). La mirada orteguiana sobre la modernidad presenta una época histórica y filosófica cuyos valores (la razón, el desarrollo industrial, la democracia y el capitalismo) abarcan a Europa y, en menor medida, a España (Pinedo 46). Asimismo, ya en 1933, Ortega presenta un diagnóstico a todas luces inquietante: la modernidad ha concluido o, en otras palabras, el buque insignia de la modernidad, a saber, Europa, se encuentra en una crisis irremediable tras el comienzo de la Primera Guerra Mundial.

Siguiendo este hilo, la llegada de los años setenta y ochenta acarrea el protagonismo filosófico de un convencimiento singular, a saber, que ha llegado una época de pensamiento débil. Así pues, los finales del siglo xx están marcados por cuatro acontecimientos cruciales generadores de un debate más o menos generalizado en torno a la condición postmoderna. Tales acontecimientos, identificados con sus correspondientes disciplinas, son: en la política, el final del Estado del Bienestar; en la ciencia, el recuestionamiento de la verdad y el desarrollo de planteamientos postempíricos; en arte, la imposibilidad de establecer normas estéticas válidas y la consecuente difusión del eclecticismo; y, en el campo de la moral, la secularización sin fronteras de los valores (GuTiÉrrez 2008). Todo esto culmina, al final del milenio, en un desánimo cultural que, apoderándose de un Occidente desgastado, se presenta como una consecuencia lógica de tantas promesas incumplidas. Un desánimo cultural generalizado que recuerda y tiene muchas similitudes, también diferencias, con la atmósfera de crisis que dejó la hecatombe de la Segunda Guerra Mundial (Rodríguez 2012). No en vano, el existencialismo surge de ahí, de ese arrastre de certezas y del abandono de los grandes y confortables relatos de aquella modernidad ahora puesta en cuestión. En efecto, una de las notas identificativas más notorias de la filosofía existencialista es su sentido posbélico, del horror y del vacío. 
Es aconsejable recordar, en este punto argumentativo, que el vocablo postmodernismo no debe equipararse al de postmodernidad y se empleó por primera vez en Italia para hacer referencia a una nueva concepción de la arquitectura llamada a superponer o combinar, en edificios nuevos, elementos de estilos arquitectónicos de épocas pasadas (Collin 61). Las críticas vertidas, desde los estudios postmodernos, a la cumbre del modernismo arquitectónico y del llamado estilo internacional fueron implacables. Así, uno de los criterios centrales de las estéticas de cuño moderno, la unidad de estilo, fue sustituido por el pluralismo de las formas o, lo que es lo mismo, por la presencia simultánea en una misma obra de puntos de vista distintos y hasta antagónicos. Llama la atención el símil entre este estilo arquitectónico postmoderno, la fusión de estilos distintos y las maneras típicamente postmodernas de tratar los temas de la subjetividad, es decir, desde ópticas múltiples. Qué duda cabe, esto no es casual. Con todo, el término postmodernidad apareció en el vocabulario filosófico de la mano de Jean-François Lyotard en su libro La condición postmoderna. Informe sobre el saber (1979), una obra cuyas ideas casaron muy bien en un momento de crecimiento de la sociedad informatizada. Al mismo autor pertenece la Economía libidinal (1974), una optimista eroticidad que se contrapone a aquella sociedad opresiva que denunciara Karl Marx y a las pulsiones mortíferas a las que diera preeminencia, frente a las aguas tranquilas de la razón, Sigmund Freud. Se trata, en definitiva, de cuestionar al humanismo ${ }^{3}$. Por su parte, en el texto El fin de la modernidad, nihilismo y hermenéutica en la cultura postmoderna (1985), Gianni Vattimo hace de lo postmoderno una adversidad al pensamiento totalitario y a la teoría moderna de la racionalidad. Más exactamente, y a través de una desconfianza respecto al poder de la razón humana en sentido fuerte, el filósofo italiano invita a renunciar a los grandes relatos modernos: a la metafísica, a la filosofía de la historia y a la teología. Y es que, dado que las interpretaciones humanas son teóricas, plurales y relativas (GARCía 201), estas son, también, débiles. En efecto, las apuestas de Vattimo se concretan en dejar atrás las lógicas férreas y unívocas, las políticas monolíticas y verticales, la soberbia de las vanguardias y el etnocentrismo de una Europa sesgada. ¿Cómo? Pues mediante el libre curso de la interpretación, el apoyo a los movimientos sociales transversales, la recuperación de las artes populares y plurales y, por último, la visión mundial de las culturas. Mención especial merece la noción de deconstrucción de Jacques Derrida en Los márgenes de la filosofía (1967), la cual se posiciona contra el imaginario moderno-positivista del progreso donde la democracia moderna se narra a sí misma en la presunción de dejar atrás todo rastro de autoritarismo. La impronta deconstruccionista, pues, tiene muy en cuenta las nuevas formas de organización social que no dejan de proliferar desde los setenta hasta la más acuciante actualidad. En efecto, se realiza un llamamiento a los nuevos agentes sociales que procuran un pensamiento político postestructural del que, por fin, podríamos esperar que quede desterrada la presunción de una solución final para el

\footnotetext{
${ }^{3}$ La crítica del humanismo como concepción ideológica es un tema central de la filosofía contemporánea.
} 
conflicto y para la historia. En este asunto, se hace imprescindible nombrar a uno de los críticos por excelencia de la moderna noción de sujeto, Michel Foucault, en su advertencia contra la comprensión unitaria y autoidéntica de la vida en sociedad (Artime 29). Lo cierto es que Foucault es de los filósofos que más han insistido en la cuestión de la muerte del sujeto. De ahí que indicase que este es una invención reciente y no el problema más antiguo ni el más constante que se haya planteado el saber humano. Es más, Foucault declara que su fin está cerca.

En fin, tanto Lyotard como Vattimo, Derrida, Foucault, entre otros, son engranajes de un todo incompleto y móvil que es el postestructuralismo en tanto propuesta que invita a dejar atrás la dialéctica y los pensamientos viciados en la compulsividad de la representación. Un postestructuralismo que, tal y como sostiene Rosi Braidotti en su Feminismo, diferencia sexual y subjetividad nómade (2004), supone una revisión teórica y epistemológica del programa emancipatorio de la modernidad y, por tanto, tiene carácter postmarxista y entronca con el espíritu del Mayo del 68.

Al margen de lo recién expuesto, y sin olvidar que Nietzsche ya había manifestado las debilidades, paradojas e inconsecuencias de la absolutización metafísica de la identidad (Mayos 387-392), nos podemos inclinar a considerar que la genealogía filosófica de la postmodernidad, sobre todo en relación con los focos que son nucleares en las reflexiones feministas, se remonta a Martin Heidegger. Identidad $y$ diferencia (1957) expone una de las ubicaciones del despertar de la filosofía de la diferencia como un intento de romper con la tradición filosófica de la modernidad y, así, poder pensar de otra manera (GARCía 201-202). Más allá del conocimiento tradicional que abraza modelos soberanistas del sujeto de raigambre cartesiana (sujeto con autoconciencia radical y racionalidad todopoderosa) y kantiana (sujeto enteramente libre y autónomo, capaz de autoplantearse el imperativo categórico). Más allá de un sujeto que es idéntico a sí mismo e inmutable a pesar del paso y los saltos del tiempo. Más allá, pues, de un sujeto que disfruta (¿o más bien sufre?) de una coherencia interna inquebrantable cuya identidad sustantiva lo individualiza (CANo 36). Además, en su artículo "La pregunta por la técnica» (1980), Heidegger hace de la metafísica occidental un discurso indisociable del desarrollo científico y tecnológico. Por ello, cuestiona la forma adoptada por la racionalidad originada en los antiguos griegos y que persiste hasta nuestros días, por estar atravesada por una apología del Sujeto como dueño y señor de la naturaleza. Una naturaleza concebida como Objeto. Heidegger, pues, se atreve a desmantelar la definición clásico-moderna de lo humano como animalidad racional, así como la concepción del tiempo en términos de historicidad lineal progresiva. En síntesis, Heidegger denuncia el discurso que sirviera a la Ilustración para alumbrar la república francesa y, de un modo general, la democracia que inspirara la emergencia del feminismo de corte humanista, universalista o racionalista. 


\section{DEL FEMINISMO A LOS FEMINISMOS}

Desde unos parámetros discursivos modernos de pensamiento, existe cierta homogeneización en la manera de entender el feminismo y, partiendo de lo que se denomina Occidente, el feminismo constituye un conjunto teórico explicativo que da suficiencia a la pensabilidad del mundo y, por ello mismo, se define como una herramienta crucial para entender la historia. Esta óptica establece que los mínimos normativos son los principios de la Declaración Universal de los Derechos Humanos (1948).

En síntesis, puede decirse que el feminismo universalista es un canon político y moral que demanda globalmente ser respetado como agenda internacional y que genera, por ello mismo, un ajuste de cuentas, de tipo tensional, con los llamados feminismos postcoloniales. Este sentido univoco del feminismo nace al calor del racionalismo, bajo la estela del pensamiento de quien inaugurara la filosofía moderna, René Descartes, pero, eso sí, como una hija respondona y no prevista. Bajo esta perspectiva, es un discípulo de Descartes, Poullain de la Barre, quien aparece como el hacedor de la primera tesis feminista. En Sobre la igualdad de los sexos (1673) Poullain de la Barre sostuvo, radicalizando los principios racionalistas cartesianos, que la inteligencia no tiene sexo.

Uno de los puntos definitorios de la modernidad es una íntima implicación entre una teoría de la racionalidad y una teoría de la sociedad. Por ello, el hecho de que el feminismo haya nacido en la modernidad no es una casualidad histórica. Es más, la emergencia feminista fue posible en el momento en que se vinculó la crítica social y la teoría de la razón, y eso fue justamente lo que se produjo en la modernidad (Campillo 168-169). De ahí que el feminismo, como crítica filosófica que se desenvuelve como crítica social, afirme que vindicar de manera radical los principios moderno-ilustrados es imprescindible a la hora de luchar por los derechos usurpados de las mujeres.

Hace tiempo ya que se declara que el feminismo, dada su capacidad para generar cambios en todas las esferas sociales, es el movimiento más importante en los últimos tiempos y, de una forma más patente, en las sociedades occidentales (Reverter 37). Como muestra de esta riqueza reproduzco a continuación un bonito párrafo de la filósofa Celia Amorós, una de las más importantes defensoras del feminismo de la igualdad en el ámbito de habla castellana que, no obstante su postura, da entrada para el análisis de un sentido plurívoco del feminismo:

Yo, por edad, fui en este país una de aquellas a las que les tocó roturar lo que ahora es el feminismo como crítica filosófica. Pero afortunadamente, me llego a ver incluso desbordada por lo que actualmente se hace en el panorama del feminismo filosófico español; se cumple aquello de 'que haya mil rosas', que decía Mao. Pues bien, las hay, hay mil rosas. Hay muchos grupos que cultivan en diferentes direcciones y orientaciones la crítica feminista (AMORós 72).

A pesar de todo lo anterior, el presente nos muestra que las direcciones de la lucha política de las mujeres entroncan con una diversificación feminista que, lejos de un obstáculo, supone un síntoma de riqueza que ha llegado para no marcharse. 
El sentido plurivoco del feminismo va de la mano de una evolución diversificacional que, sin embargo, no pierde su estatuto de foco de vanguardia. Movimiento teórico y práctico en constante renovación, el feminismo se ha especializado en los diversos campos de estudio, extendiéndose a través de derivas académicas y militantes diferentes y, en algunos casos, contrapuestas. Asimismo, al inyectarse en todos los campos de conocimiento, ha supuesto un cambio radical en la forma de concebir y estudiar la realidad. Consecuencia de todo ello es la revisión feminista (contundente) de lo que se ha llamado tradicionalmente el canon filosófico. Después de todo, pese a las diferencias entre los discursos filosóficos, este canon se ha mantenido de una manera homogénea y a pesar de su mayor o menor explicitación, salvaguardando un concepto de sujeto que, asumido acrítica y abstractamente como varón, ha permanecido en la base de las filosofías oficiales, aclamadas y divulgadas a lo largo de la historia. En este punto, fructífera ha sido la complejidad del feminismo de la diferencia de cuńo italiano que, desechando los tratamientos tradicionales de la filosofía respecto al cuerpo, hizo de este el lugar de la experiencia, la subjetividad y la política. El llamado cuerpo no discursivo, es decir, no reducible a la representación o a la ideología, es el sitio donde se ancla la experiencia de las mujeres. De ahí que la política del feminismo italiano se base en la diferencia sexual y repudie los componentes puramente racionales de la identidad propia del humanismo, sobre todo su autorrepresentación, homogeneidad y estabilidad.

Es claro que cada vez se hace más complicado asentar unas bases comunes que unifiquen los pensamientos, acciones e investigaciones feministas. Sin embargo, tales diversificaciones tienen un lugar común al concebirlas como planteamientos que se oponen, y proponen alternativas, frente a los modelos asimétricos de poder que privilegian a los hombres y subordinan a las mujeres. Tanto los feminismos de la igualdad como los feminismos de la diferencia tienen como punto de encuentro una posición de denuncia frente a las relaciones desiguales (que no diferentes) entre mujeres y hombres. Cómo interpretar las desigualdades por razón de género, así como cómo combatirlas es lo que especificará las plurales posiciones feministas (REVERTER 37). Las alternativas propuestas por el feminismo ilustrado y nominalista, por la democracia multicultural y deliberativa, por la democracia radical y por la democracia paritaria son alternativas que dejan lejos la imposición de un único modelo. A fin de cuentas, qué se entiende por lo político y por ciudadanía está constantemente en juego, así como, por supuesto, la idea misma de democracia (CAMPILlo 172). No en vano, ya son muchas las voces que alertan de que la democracia representativa se encuentra en un momento de crisis por no satisfacer las necesidades actuales de una ciudadanía plural, diversa y en constante movimiento.

Ahora bien, la crítica arremetida desde la igualdad y los valores ilustrados a los sesgos patriarcales de género (por dejar fuera a las mujeres del ejercicio de una humanidad plena) se relaciona con la crítica con que los feminismos de la diferencia embisten contra la lógica occidental binaria y excluyente que valora de una manera peyorativa a las mujeres, así como a todo lo que con ellas se relaciona. Asimismo, los universos de la igualdad y la diferencia divergen significativamente respecto a la noción de vindicación. Esta alude a la exigencia de aplicar a las mujeres todos los derechos (civiles, sociales y políticos) que ya poseen los varones. Así, mien- 
tras los feminismos de la igualdad hacen de la vindicación su núcleo programático, los de la diferencia proponen su rechazo y enfatizan las singularidades propias de las mujeres. El acento postmoderno de estos feminismos, siguiendo la explicación de Richard Tarnas (1991), les hace constatar que los grandes relatos han caído, así como la idea de razón, profundamente masculinizada, que los sustenta. En efecto, la universalidad no es un valor al que sea posible, ni conveniente, aspirar. Porque la postulación de un medio homogéneo de racionalidad situado por encima de los discursos particulares ha quedado atrás.

En este punto del análisis, cabe explicar un apunte respecto a las similitudes entre, por un lado, la igualdad y los planteamientos marxistas y, por otro lado, la diferencia y el psicoanálisis. En sus inicios teóricos, el feminismo se aproximó, por ciertos intereses programáticos y de articulación como movimiento social estructurado, a ciertos pensamientos críticos como el marxista, el cual identificaba diversas relaciones de dominación y subordinación, universales, en la sociedad (Сово 20-21). Sin embargo, las herramientas marxistas de acercamiento y denuncia a la realidad política y social resultaron ser insuficientes para abordar la complejidad de los análisis situacionales de las mujeres. El feminismo, pues, supuso un talante innovador al colocar como núcleo de sus análisis a un nuevo sujeto social antes obviado: las mujeres. Por otro lado, fueron los elementos más criticados del marxismo (su marcado evolucionismo social, su desatención de los aspectos ideológicos y culturales y su confianza absoluta en el proletariado como único sujeto de la transformación social) lo que provocó que diversos feminismos de la diferencia (así como los nuevos movimientos sociales) combinaran sus propuestas de liberación con el psicoanálisis, que aportó herramientas para repensar la construcción normativa de la feminidad y de la masculinidad. Relacionado con esto, los feminismos de la diferencia siguieron la estela crítica de la deconstrucción de la metafísica y del sujeto, que fue vista como una noble estrategia filosófica que intentaba acceder a todo lo expulsado, impensado o etiquetado como exterior a la razón. Así las cosas, si bien la igualdad ha sido un objetivo que ha dado sus frutos en los campos legal y político y también, aunque de una forma más tímida, en las esferas laboral y económica, los feminismos de la diferencia problematizan las aspiraciones igualitarias. Su argumentario más socorrido es que tales aspiraciones igualitarias encubren un deseo de reproducir el entramado normativo masculino. Y, al margen de las simparías o antipatías que generen tales aseveraciones, lo cierto es que a medida que la lucha por la igualdad de oportunidades ha alcanzado importantes éxitos, los discursos de la diferencia han ido ganando más terreno en la teoría feminista (Reverter 39). Sobre todo, en la incidencia de la alteridad, las orillas, las fronteras y, en definitiva, de los márgenes.

Vistas así las cosas, han sido variadas las críticas con que el feminismo de la igualdad ha embestido contra los feminismos que comparten posiciones con lo postmoderno y su afirmación de la diferencia (y el consiguiente recelo hacia las tendencias igualitaristas). Entre estas críticas, una de las más repetidas consiste en afirmar que la extensión de la diferencia al colectivo de las mujeres hace imposible, o por lo menos muy difícil, la constitución de un sujeto político colectivo y, por tanto, queda obstaculizada la construcción de un marco normativo para el feminismo como movimiento social estructurado (Сово 25). Ante esto, los feminis- 
mos de la diferencia y su indisociable afán particularista argumentan que el ideal de igualdad que abanderan las feministas universalistas es un concepto altamente controvertido. No extrańa, pues, que lo hayan acusado como un obstáculo para las diferencias o, en otras palabras, como un neutralizador de lo femenino. Y lo femenino es, a fin de cuentas, lo siempre desterrado, olvidado, excluido e infravalorado por una cultura androcéntrica y centrada en los valores asociados a la masculinidad. Este tipo de argumentaciones desde los feminismos particularistas es lo que ha llevado a Judith Butler a afirmar que reconocer al otro en su diferencia es una instancia sin la cual el quehacer feminista se hace partícipe de las maniobras excluyentes $\mathrm{y}$ violentas de los dominadores.

\section{LAS CRÍTICAS A JUDITH BUTLER COMO CRÍTICA A LA POSTMODERNIDAD}

De las interpretaciones disidentes más leídas y difundidas frente a la postmodernidad, destacan la de Terry Eagleton en Las ilusiones del postmodernismo (1997) y Frederic Jameson en El postmodernismo o la lógica cultural del capitalismo tardío (1984). Para el primero, la postmodernidad es ante todo un estilo de pensamiento que desconfía de las nociones clásicas de verdad, razón, identidad y objetividad, así como de las ideas de progreso universal, emancipación, estructuras aisladas y, en definitiva, de los grandes relatos o de los sistemas de explicación que se pretenden definitivos. En efecto, la postmodernidad establece, en contra del clima optimista del iluminismo, que el mundo es contingente, inexplicable, inestable e indeterminado; algo así como un conjunto de culturas desunidas y de interpretaciones diversas. Todo ello engendrador de escepticismo frente a la verdad, la objetividad, las normas... y, también, frente a la coherencia de las identidades. Porque nada hay dado en la naturaleza. Para el segundo, Jameson, la postmodernidad es una cultura global, fundamentalmente estadounidense, que expresa de manera superestructural una nueva ola de dominación militar y económica. No en vano, Jameson afirma que en esta vertiente de pensamiento, reino de la paradoja y el pastiche, sobresale una nueva superficialidad que se prolonga tanto en la teoría contemporánea como en toda una nueva cultura de la imagen y el simulacro.

En un sentido similar, los feminismos que siguen la estela universalista y humanista propia de los parámetros del pensamiento moderno reclaman de manera habitual que la relación entre la lucha de las mujeres (por superar discriminaciones y violencias) y alguna de las corrientes que constituyen el complejo mosaico de la postmodernidad es problemática y complicada. Por eso, una de las cuestiones que enseguida se ponen encima de la mesa es si es posible un feminismo postestructuralista, dado que el feminismo necesita de una identidad compartida. La respuesta de Butler es clara: abrir no implica destruir y, en efecto, proponer una noción abierta de mujeres no implica dejar a los movimientos feministas sin su punto de apoyo. Se trata, en definitiva, de no cerrar los significados de antemano: 
Nunca la cuestión fue establecer si debe hablarse o no de mujeres. Se hablará y, por razones feministas, debe hablarse; la categoría de mujeres no se vuelve inútil mediante la deconstrucción, sino que se convierte en una categoría cuyos usos ya no se reifican como 'referentes' y que presenta la oportunidad de que se la abra o, más precisamente, de llegar a significar de manera que ninguno de nosotros puede predecir de antemano (Butler 55).

Por otra parte, consideramos que es urgente reflexionar sobre si el debate entre la modernidad y la postmodernidad ha influido en las disputas internas del feminismo o, más bien, si el desarrollo de las disputas feministas ha supuesto una revolución teórico-práctica de tal calado que se ha hecho pertinente un replanteamiento general del abordaje filosófico, social, cultural e, incluso, natural de nuestra sociedad que, es evidente, incide de manera directa en lo que podamos entender por subjetividad y, además, por lo que sea la responsabilidad y por la posibilidad de la acción política. No en vano, las reflexiones de la diferencia tienen lugar como consecuencia (¿o tal vez síntoma crítico?) de la consolidación del neoliberalismo y la globalización, que generaron un clima de descrédito político que fomentó prácticas políticas de (y en) los márgenes y los afueras de la política institucional.

En esta órbita, los movimientos sociales están llamados a propiciar el cambio del sentido de la política, desplazándolo desde su concepción moderna como arte de lo posible a encuadrarlo en un salto, una discontinuidad que produce una inflexión de lo posible a lo imposible. Es decir, lo imposible señala la diferencia que se abre. Se trata, en definitiva, de inaugurar una nueva forma de pensar, una nueva lógica que es la lógica de la alteridad. De ahí el énfasis en los componentes expresivos, lúdicos y teatrales y en los «otros» postulados políticos a los institucionales que los nuevos movimientos sociales tratan de vehicular ${ }^{4}$, rompiendo con el ideal modernista de progreso y adoptando una actitud de desconfianza hacia la racionalidad técnico-industrial (MAYOBRe 133-134) y la civilización de base productivista que conlleva.

Al margen de las notables cercanías y afinidades, no es lícita una traslación sin reservas y en bloque de la autora de El género en disputa (1990) al modo de ver o paradigma transmoderno. Más bien, el enfoque transmoderno de Butler es posible tras aplicar a aquel las cuestiones sexogenéricas que la autora ha puesto sobre mesa y que se ha convertido en un motivo inexcusable dentro de los debates feministas actuales. Unos debates que, no dando señales de clausura ni agotamiento, muestran que la pluralidad de tendencias feministas no cesa de crecer como síntoma de madurez teórica. Tanto es así que nos parece no exagerar si concibimos a tales ramificaciones feministas como inabarcables.

En su segunda gran obra, Cuerpos que importan (1993), Judith Butler puso de manifiesto que su teoría de la performatividad de género había sido (mal)interpretada por un gran número de lectoras y lectores, como si ella hubiese afirmado que cada persona puede despertarse «cada mañana, examina(r) el guardarropa [...]

\footnotetext{
${ }^{4}$ Por ejemplo, la desobediencia civil de Thoreau, la no violencia de Gandhi o de ayuda mutua de Kropotkin.
} 
en busca del género que quiere elegir y [asignárselo] durante el día para volver a colocarlo en su lugar por la noche» (12). Pero no solamente las reacciones críticas hicieron de la obra de Butler un cúmulo de aportaciones ilusas que, dentro de una nube de bienestar económico, ignoran la violencia que sufren muchas mujeres. La extracción descontextualizada de algunas de sus frases, como «la risa frente a las categorías serias es indispensable para el feminismo" (28), ha ayudado a las lecturas voluntaristas y banales de sus textos, como si Butler apostara por un peligroso desplazamiento de lo ético y lo político a favor de lo lúdico y lo estético (Burgos 15-28). Por otro lado, y esta ha sido la línea refutadora más usual, las tesis de Butler han sido consideradas deudoras de filosofías de corte postmoderno y determinista y, en efecto, han sido tildadas como ineficaces a la hora de encajar con los objetivos emancipadores del feminismo. Una de las razones principales de esta opinión es, según Butler, que todo intento de aunar feminismo y postmodernidad se considera, desacertadamente, algo a temer e incluso como un síntoma de los pasos que se han dado hacia atrás en la historia de la lucha de las mujeres. De hecho, es muy usual interpretar los planteamientos no modernistas como una suma confusa de teorías que aplauden los intentos irracionales (Femenías 137) de abocar al ser humano hacia un irresponsable relativismo cultural.

Sea como fuere, ha sido la tradición ilustrada la que ha mostrado mayores dificultades para digerir las intervenciones de Butler, toda vez que esta ha llevado a cabo una aguda problematización respecto a las relaciones entre el género y la igualdad, así como una comprensión de la subjetividad corpórea no asumible bajo la tradición racionalista que arranca con Descartes y que no sirve para poner en cuestión lo que, por darse por sentado, se vuelca como mecanismo de legitimación política. De hecho, en Cuerpos que importan, Butler afirma que "problematizar la materia de los cuerpos puede implicar una pérdida de certeza epistemológica, pero una pérdida de certeza no es lo mismo que el nihilismo político» (56-57). Butler, en un claro afán por escapar de aquellos parámetros liberales de acción, propone una subjetividad derivada y no originaria que, no obstante, no destruye al feminismo en tanto fuerza política de transformación social. Todo lo contrario. La reformulación butleriana de la subjetividad como un efecto abre unas posibilidades de acción para las que son ciegas las posiciones feministas de corte ilustrado y, por ello mismo, constructivistas y esencialistas.

En fin, las opiniones que refutan la conveniencia de combinar el feminismo y lo postmoderno descansan en la tesis de que, tal y como ha explicado Lidia Puigvert, estos no son ni intelectual ni políticamente aliados: mientras el feminismo refuerza las posibilidades de las personas mediante las conquistas democráticas, la postmodernidad socava esas posibilidades y desarticula en la teoría y en la práctica las aspiraciones transformadoras. Dado esto, una pregunta crucial que Butler plantea es de qué manera puede rescatarse la capacidad de acción sin caer en el voluntarismo, que deriva en fiesta e ilusiones y escasa o nula visión comunitaria, ni en el determinismo, que convierte a los seres humanos en entidades tan sujetadas al contexto que no pueden realizar labores críticas.

En su obra La herejía lesbiana (1993), Sheila Jeffreys analiza la filosofía performativa de Butler y la denomina nueva estrella del pensamiento lesbiano y gay. 
A pesar de compartir el objetivo de "poner en entredicho que la sexualidad sea un hecho natural, desenmascarándola como una institución política» (17) y cuestionar el imaginario médico que hace del lesbianismo una anomalía congénita, un efecto de una psicología deteriorada, una desviación o un fruto más de la omnipresente envidia del pene, la lectura de Jeffreys es de las más beligerantes. Nótese que La herejía lesbiana salió a la luz el mismo año que Cuerpos que importan, un libro donde Butler responde a las acusaciones y dudas que planteara su primera gran obra, El género en disputa (1990). Bajo la óptica de Jeffreys, Butler propone un paradigma «brutalmente determinista y pesimista" (154) que convierte al falocentrismo en inevitable: un retorno al género en la medida en que sostiene que no es posible escapar de la formación generizada de la subjetividad y, derivado de aquí, hacer uso del género puede ser, y de hecho lo es, una forma de acción política en contra de los mismos regímenes opresores. Regímenes que, además, son los lugares donde la normatividad de género se mantiene a través de la coacción: el género se entiende como algo «despolitizado, aséptico y de difícil asociación con la violencia sexual, la desigualdad económica y las víctimas mortales de abortos clandestinos» (17). Y, aparte del retorno al género, la filosofía de Butler se ancla a una incertidumbre radical respecto a las identidades lesbiana y gay que pretende erradicar, a toda costa, «incluso el concepto de una identidad temporalmente estable» (162). La multimanía butleriana, como esquivar cualquier esencialismo, o evitar el etnocentrismo o dejar siempre claro que no persigue objetividad ni neutralidad alguna, la lleva a afirmaciones que, a juicio de Jeffreys, son ofensivas. Tanto más cuando mientras «los regímenes reguladores conservan sus certezas, tal vez la mejor forma política de combatirlos sea mantener también nosotras algo de certeza sobre quiénes somos y qué estamos haciendo» (167). Sin ir más lejos, Jeffreys recuerda cómo, en un congreso en 1989, Butler comenzó su intervención "con una angustiada introspección sobre quién es ella ante una solicitud de dar una conferencia como lesbiana» (165), lo que obedece al nudo rector de su obra, a saber, que las categorías de identidad suelen ser instrumentos de un régimen regulador. Así lo explica la propia Butler en su «Imitation and gender insubordination» (1991):

Las categorías de identidad tienden a ser instrumentos de regímenes regularizadores, tanto si actúan como categorías normalizadoras de estructuras opresivas como si sirven de puntos de encuentro de una oposición liberadora de esa misma opresión (ButLer 86).

Para Jeffreys, pues, las propuestas butlerianas, así como las de Diana Fuss, generan una peligrosa «fragmentación de la comunidad lesbiana a consecuencia de los ataques contra la política feminista» (14). Vistas así las cosas, Jeffreys opina que Butler es exponente de una teoría operativa a los tiempos conservadores que conducen, ni más ni menos, que «al fatalismo y a la inacción» (21), además de a ridiculizar al feminismo que la propia Jeffreys profesa. La afinidad de la filosofía butleriana con la denominada postmodernidad es buena parte de los motivos por los que Jeffreys acusa a Butler. $Y$ es que la postmodernidad, o postmodernismo como refiere ella, es una corriente que apunta a la creación de un universo alternativo y 
cree, de manera errónea, poder acabar con la denominada «sado-sociedad» en la que la humanidad está inmersa:

[las] ideas postmodernas [...] están derivadas habitualmente de los escritos de los intelectuales franceses, que no tuvieron en cuenta a las mujeres y mucho menos a las lesbianas; [y, en efecto] son adversas a la política del feminismo lesbiano (JeFFrEYs 20).

Dado esto, es claro que Jeffreys hace del lesbianismo, entendido como elección, una opción radicalmente feminista: la elección lesbiana es, en sí misma, revolucionaria y transformadora. Jeffreys, al proclamar que «el lesbianismo es feminista y el feminismo lesbiano» (15), hace del feminismo lesbiano el movimiento más válido a la hora de aspirar a una sociedad liberada de servidumbres. En síntesis, La herejía lesbiana (1993) señala con rotundidad que tanto Fuss como Butler homogeneizan a las lesbianas y a los gais, convierten al género en un juego y al feminismo en un divertimento. En efecto, desatienden aquellas relaciones de poder que estructuran la vulgar y verdadera opresión de las mujeres. Estas carencias aluden a un marco teórico específico, el del liberalismo idealista, que apoya y da sentido al "proyecto libertario sexual y, más concretamente, el sadomasoquista [y anula] el proyecto feminista de los últimos veinte ańos» (150-154).

La filósofa Seyla Benhabib es una de las representantes más notorias de un actualizado feminismo ilustrado de la igualdad. Ubicada en la tradición de la Teoría Crítica, propone un alejamiento de las formas postmodernas de pensamiento en tanto malas aliadas en lo que respecta a la recuperación de la capacidad crítica feminista. Así, afirma que las estrategias subversivas que propone Butler, tales como la parodia o la resignificación, son triviales e ineficaces.

A su juicio las propuestas de Butler son incompatibles con cualquier lucha política emancipadora y, en efecto, esté allende los objetivos liberadores feministas. Al igual que Jeffreys, Benhabib considera que los puntos más denunciables de la obra de Butler son aquellos que se deben a su filiación postmoderna, que, como tal, prescinde de cualquier horizonte utópico que aúne a toda la humanidad en una meta para mejorar la vida en términos universales. El gran peligro de la postmodernidad en general, y el de la propuesta butleriana en particular, es que muestran una visión del yo como producto, y no como origen, de la agencia. Entender así la subjetividad conlleva cargarla de fragilidad y tenuidad, unas características que ya son de por sí propias de la subjetividad femenina.

Cualquier teoría sin sujeto, como la de Butler, bloquea las nociones de responsabilidad, autonomía, decisión, libertad, y, por tanto, nunca podría ser considerada como feminista. Tampoco podría iniciar reivindicación social alguna. Por ello, la pregunta que Benhabib, con ánimo refutador, formula a la autora estadounidense es «si no hay sujeto, ¿quién habla?» (BENHABIB 52). La autoincoherencia es el destino final de las apropiaciones feministas de Nietzsche, tal y como es el caso de Butler, que proclaman la muerte del sujeto.

Por lo dicho, Benhabib considera que en nuestra contemporaneidad están siendo minadas algunas de las bases del pensamiento occidental, por lo que pro- 
pone pensar cuáles de las críticas presentes debería asumir el feminismo, y cuáles no. Además, las críticas en torno a la muerte del sujeto, así como la de la historia o la de la metafísica, pueden articularse en sentido débil o en sentido fuerte, a lo nietzscheano, incompatible con los objetivos feministas. Por ejemplo, Benhabib plantea que, dado que Butler niega, siguiendo el rastro del "no hay ser detrás del hacer» (NieTzSChe 52) de la Genealogía de la moral, la identidad de género más allá de su dimensión expresiva, cómo podríamos cambiar la inercia de esa misma actuación o expresión, o, mejor dicho, desde dónde. La reducción de la agencia femenina a una agencia sin agente merma los proyectos de autonomía de las mujeres:

[La teoría de Butler] no sirve para explicar la capacidad de actuar humana [porque] el yo butleriano nos remite a Orlandos que se expanden, no a lo largo de los siglos, sino solo en el breve tiempo de vida, atrapados en el perfecto torbellino de la falta de unidad del género, tiempo y espacio (Benhabib 163).

En síntesis, Benhabib sostiene que la obra de Butler nos conduce a un determinismo de corte social (BuRgos 523). Un determinismo que se apoya en dos principios inasumibles para cualquier proyecto feminista, a saber, la inexistencia de un yo prediscursivo y la visión del cuerpo y el sexo como instancias no naturales sino naturalizadas (Prado 169).

El pensamiento de Martha Nussbaum se encuadra en un liberalismo político que se inspira en la teoría de John Rawls. Según su lectura, expuesta sobre todo en The profesor of parody (1999), Butler concibe el cambio político en términos de una performance paródica (SMIRAgLia 445). El consuelo paródico de los actos performativos subversivos es el único espacio, individual, de resistencia (SMiraglia 446). Si bien El género en disputa (1990) no es sino un texto sofista que no hace verdadera filosofía y que produce una teoría incompatible, inconsistente y sustentada en una retórica muy confusa que, en realidad, no aporta nada nuevo, Lenguaje, poder e identidad (1997) se reafirma en la imposibilidad de cualquier reivindicación política de carácter colectivo. Incluso las relativas a las libertades públicas y los derechos humanos. Y es que, al ser convertido en comedia, cualquier planteamiento político queda vaciado: la posición de sujeto, al perder fuerza, hace emerger la debilidad de los compromisos y, en último término, solo importan los asuntos individuales.

En definitiva, la crítica butleriana al sujeto deriva del cuestionamiento llevado a cabo por Hume hace ya siglos y no merece la pena seguir insistiendo. Más cuando la obra de Butler, sigue argumentando Nussbaum, remite a la típica forma de pensar de un sector de la sociedad estadounidense, acomodado en un estado de bienestar y alejado de las luchas materiales y, por ello mismo, reales. Dicho de otro modo, Butler ignora aquellos aspectos corporales que no son susceptibles de manipulación corporal. Al proclamar que no hay víctimas en el trabajo de Butler, Nussbaum deja claro cómo se posiciona en la línea de Susan Bordo en su «Feminism, post-modernism and gender-scepticism» (1989): las propuestas butlerianas son definidas como un escepticismo feminista sobre el género que se relaciona con ciertas tendencias postmodernas empeñadas en textualizar totalmente el cuerpo. Además, Bordo afirma que Butler otorga a los significados una especie de juego libre y crea- 
tivo a costa de la atención que merece la ubicación material del cuerpo en la historia y, en efecto, salta una pregunta a su juicio insoslayable, a saber, "chay un cuerpo en este texto?» (Nussbaum 37-45). De esta manera, Nussbaum y Bordo, así como Carol Bigwood, Lynne Segal y Lynne Pierce, hacen de la obra de Butler una teoría que no da cabida a las cuestiones vinculadas al cuerpo femenino en su aspecto material. En fin, si bien Celia Amorós, tal y como explicaremos a continuación, hace del feminismo y la postmodernidad una relación peligrosa, Nussbaum la cataloga como trágica. Butler es uno de los síntomas del quietismo político contemporáneo, esto es, de la pérdida de un sentido del compromiso público en tanto enfatiza los gestos simbólicos de la vida y olvida la materialidad del sufrimiento.

En Tiempo de feminismo (1997), Celia Amorós argumenta una analogía entre los mecanismos, propios de la postmodernidad, para enfrentarse al proyecto de cuño ilustrado y los del «romanticismo cultural y político» (304). Concluye, como adelantamos antes, que la relación entre postmodernidad y feminismo es peligrosa. El vínculo que el feminismo comparte con la radicalización de los ideales de la Ilustración es «un vínculo del que no se puede renegar» (323).

Aunque Amorós esquiva la tentativa de creer en un sujeto que se autogenera de una manera completamente autónoma, niega «la validez de ciertas reducciones, como la del sujeto a la de un significado ya constituido desde el cual no podría decirse en rigor que habla, sino que es hablado» (Amorós 318). De aquí deriva el escepticismo que muestra ante las muertes (como las de sujeto) proclamadas por muchos de los abanderados de la postmodernidad. Y es que son, según Amorós, muertes prematuramente celebradas. Asimismo, cabe destacar que, además de Tiempo de feminismo (1997), la obra compiladora Feminismo y Filosofía (2000) también contiene refutaciones hacia la comprensión butleriana del género, esto es, en unos términos performativos que lo definen cual una práctica citacional que le lleva a tomar como estrategia política la apropiación «de la fuerza del lenguaje ofensivo de una forma inadecuada» (Butler 72). De una manera más concreta, Amorós extrae la tesis de Butler de que el género «no es un acto único, sino una repetición y un ritual que logra su efecto mediante su naturalización en el contexto de un cuerpo, entendido, hasta cierto punto, como una duración temporal sostenida culturalmente» (BuTLER 15) y lo somete al llamado test de Fraser's. Las aportaciones de Butler, en vez de atender a las necesidades teóricas y prácticas de las mujeres, se limita a una proposición poco menos que banal: la proliferación paródica de los estereotipos genéricos con finalidades subversivas o transgresoras poniendo todas las resignificaciones a un mismo nivel de deseabilidad. Ahora bien, después de aproximarnos a algunas de las opiniones más críticas sobre Butler, nos podemos plantear si acaso son actos performativos paródicos todo lo que la obra de Butler nos ofrece a las feministas (Smiraglia 447).

5 El llamado test de Fraser analiza y valora las teorías feministas para sacar a la luz a aquellas que son idóneas y pertinentes frente a las que no priorizan visibilizar la subordinación de las mujeres $y$, por tanto, han de ser desechadas. 
En definitiva, las críticas a Butler pueden dividirse en dos grupos. Las que emergen de lecturas voluntaristas y las que provienen de interpretaciones deterministas.

La conversión de la obra de Butler en una serie de textos vinculados a un férreo determinismo social y lingüístico se basa en su noción de agencia del individuo y las posibilidades de acción política (SMIRAgLia 445), considerando que el sujeto de Butler está determinado por los discursos de poder y sus normas de opresión. Por tanto, la humanidad queda concebida como presa sin esperanza de liberación, ya que cualquier posible reforma es funcional al mismo sistema que intenta cambiar. Las normas opresivas de poder no pueden transformarse de una manera radical. Sin embargo, la performatividad de género está dentro de normas culturales que no se pueden transgredir de manera radical y total, sino que se pueden subvertir mediante resignificaciones o, dicho de otro modo, de cambios en lo que significa ser hombre o ser mujer a partir de actos cotidianos. Butler no proclama una absoluta imposibilidad en cuanto a distinguir las acciones deseables de las no deseables. Es más, reconoce dos tipos de convenciones, las hegemónicas o dominantes y las menores o subordinadas. Y es la hegemonía de algunas convenciones, precisamente, la razón para contestarlas (REVERTER 173).

Por otro lado, Butler explica que el error interpretativo de quienes han visto en su obra intenciones voluntaristas y sobreacomodadas en lo económico ha consistido en confundir la teoría performativa del género con las teorías de la acción teatral. Esta simplificación es deudora del sociólogo Erving Goffman, que entiende la performatividad de género como una forma de autoconstitución donde el sujeto hace un uso consciente de su cuerpo con el fin de producir distintos efectos. Estigma (1963) es una obra que relaciona la estigmatización con la deshumanización y explica, por tanto, cómo quien está estigmatizado no es aceptado en virtud de su no-plena-humanidad. O sea, que está fuera. No en vano, la noción de estigma hace referencia «a un atributo profundamente desacreditador» (13). Además, una persona puede ser estigmatizada por varias razones: deformidades físicas, defectos de su carácter (donde entraría la homosexualidad como estigma) y por cuestiones de etnia, nación o religión (14).

Sea como fuere, Butler participa de cierta manera del argumento de Goffman, sobre todo respecto a la relación entre la identidad estigmatizada y la representación: quienes representan a los estigmatizados acaban convirtiendo al estigma en una profesión. Nótese que Butler afirma que la representación, lejos de ser posterior a la identidad del grupo a representar, más bien condiciona lo representado. Dada la concepción de las identidades como derivaciones, Butler asevera que la representación se extiende solo a lo que puede reconocerse como un sujeto, y este sujeto reconocido es, como tal, producido mediante ciertas prácticas excluyentes:

La construcción política del sujeto se realiza con algunos objetivos legitimadores y excluyentes, y estas operaciones políticas se esconden y naturalizan mediante un análisis político en el que se basan las estructuras jurídicas. El poder jurídico produce irremediablemente lo que afirma solo representar; así, la política debe preocuparse por esta doble función del poder: la jurídica y la productiva (BUTLER 47-48). 
Es claro que Butler se alía con la postmodernidad en tanto esta proclama como imposible el sujeto como una entidad que decide desde su libre deseo y, por tanto, inhabilita el supuesto moderno de que la formación, y posterior habilitación de los seres humanos para la acción, debe entenderse desde la existencia de un sujeto previo, prediscursivo y autónomo que persigue una serie de fines. Butler defiende de manera explícita una concepción de la subjetividad derivada, no originaria, que bloquea las aspiraciones de las políticas de cuño liberal. Unas políticas que, como sabemos, están relacionadas con la manera de pensar que germina a partir de la filosofía individualista de Descartes, incapaz de construir relaciones humanas basadas, no en la estrategia y la competencia, sino en la cooperación y la solidaridad.

En síntesis, la posición de Butler no puede encuadrarse en ninguna de las lecturas anteriores. Voluntarista no es un sujeto cuya agencia emerge, no de sí mismo, sino del contexto social que le otorga sentido. Un agente no podría nunca, pues, manipular o elegir su identidad de género; eso remitiría a la postulación de un sujeto libre y soberano de voluntad y conciencia. Y determinista no es una filosofía de la libertad que pretende, ante todo, desbordar las categorías binarias para reconocer a las personas más allá de la identidad sexogenérica heterosexista o, lo que es lo mismo, cuestionando los mandatos de la matriz heterosexual y sus intereses específicos reproductivos. Entonces, es lícito reconocer en la obra de Butler un audaz intento de escapar, con sus nociones de identidad y género, de las tendencias a que nos hemos referido. Es por ello por lo que, más allá del determinismo y del voluntarismo, afirma que es posible actuar aunque, o precisamente porque, todo sujeto está irremisiblemente situado en una red de normas.

Y, por último, no quisiéramos dejar a un lado el hecho de que Butler también ha sido criticada dada la densidad, espesores sintáctico y gramatical e incluso deliberada oscuridad de su escritura, en aras de alimentar tanto la mistificación y la importancia de su obra como la dependencia de su palabra autorizada para la interpretación de su teoría (SMiraglia 445). Sin embargo, hay que tener en cuenta que la obra butleriana se aleja de la linealidad lógica argumental por participar en una interdisciplinariedad irreductible como una apuesta filosófica que es completamente coherente con el sentido de liberación de sus propuestas. Butler rechaza la noción cerrada de sistema y, en efecto, reconoce que la búsqueda de un todo coherente en sus obras es un exceso que debe abandonarse. Asimismo, cada nuevo planteamiento ilumina, mediante resignificaciones, los anteriores. En este sentido, Butler responde ante quienes le achacan presentar un lenguaje oscuro de manera intencional:

[quizás se esté subestimando] al lector, su capacidad y su deseo de leer textos complicados y que constituyan un desafío cuando la complicación no es gratuita, cuando el desafío sirve para poner en duda verdades que se dan por sentadas, cuando en realidad dar por hecho esas verdades es opresivo [...] ¿Quién inventa los protocolos de 'claridad' y a qué intereses sirven? ¿Qué se excluye al persistir en los estándares provincianos de transparencia como un elemento necesario para toda comunicación? ¿Qué es lo que esconde la 'transparencia'? (BUTLER 23). 


\section{A MODO DE CONCLUSIÓN. LA TERCERA VÍA DE JUDITH BUTLER}

Judith Butler no puede considerarse una reproductora acrítica de los instrumentos teóricos que sustentan el paradigma de la postmodernidad. Sus reservas ante los intentos interpretativos de ubicar su pensamiento dentro de las vertientes que forman parte del cuadro, o suma de cuadros, de la teoría filosófica contemporánea se repiten a lo largo de su obra. Por ejemplo, ya en 1991, la autora expresa que

[no entiende] el concepto de 'teoría', ni [le] interesa que se [le] adjudique el papel de defensora de una teoría [...] Además, la teoría nunca es mera theoria en el sentido de contemplación desinteresada, sino que es totalmente política (BUTLER 87-88).

No obstante, a pesar de afirmaciones como esta, la mayoría de los discursos detractores sobre la autora estadounidense sostienen que el contenido de su filosofía, al estar vinculada a posiciones postmodernas, merma, y acaso destruye, el sentido moderno del feminismo, es decir, su fuerza política en tanto movimiento vindicativo.

Tras revisar los usos habituales del término postmodernidad, Butler sostiene que una cierta concepción de lo postmoderno está articulada con un temible afán condicional o, incluso, con una suerte de desdén paternalista hacia todo lo que es joven e irracional (Femenías 137). Lo que de aquí se desprende es que, en opinión de la autora estadounidense, el movimiento multidimensional denominado postmodernidad ha sido entendido de una manera desacertada, esto es, como una suma confusa de teorías que no pueden evitar, e incluso facilitan, el abocamiento del ser humano hacia un crudo e irresponsable relativismo. En contra de esta tendencia interpretativa, Butler asevera que la expresión pensamiento postmoderno tiene un sentido a todas luces productivo que es, justamente, la óptica a la que se adhiere y reconoce su deuda. La postmodernidad implica una crítica rigurosa al funcionalismo político que, por su empeño de ofrecer certezas absolutas, responde a unos imaginarios de raíces profundamente metafísicas. Apuesta por el ejercicio crítico que vincula la teoría, siempre incomprensible sin su perfil material, al poder. En efecto, ciertos planteamientos postmodernos no podrían jamás caer en posturas nihilistas o relativistas. Butler, de hecho, afirma en Cuerpos que importan. Sobre los limites materiales y discursivos del 'sexo' (1993) que "problematizar la materia de los cuerpos puede implicar una pérdida de certeza epistemológica, pero una pérdida de certeza no es lo mismo que el nihilismo político» (56-57). De hecho, ya de lleno en el complejo mosaico de la postmodernidad y desde posiciones postestructuralistas, se argumenta que el prefijo «post» se refiere, más que a un «anti», a un «más allá». Por consiguiente, no se desconocen ni se desprecian los hallazgos del estructuralismo en tanto corriente concebida como un lugar por donde hay que pasar y, de manera efectiva, ya se ha pasado. Y, si bien el postestructuralismo utiliza la noción de estructuras en el desarrollo de sus análisis, invita a cambiar su concepto y, de manera sobresaliente, a tematizarlas como abiertas. Es este fomento y apuesta postestructuralista de apertura lo que ha inspirado buena parte de las reflexiones discrepantes de Judith Butler respecto al feminismo de corte igualitario. De ahí que la pensadora estadouni- 
dense nos inste a participar en la apuesta de considerar los conceptos identitarios como abiertos, contingentes y en constante e infinita revisión (GARCía 70). De la fusión entre el postestructuralismo y el feminismo, Butler aclara que

no se [trata] de 'aplicar' el postestructuralismo al feminismo, sino de exponer esas teorías [postestructuralistas] a una reformulación específicamente feminista [...] el postestructuralismo se considera algo unificado, puro y monolítico. Pero en los últimos años esa teoría, o conjunto de teorías, se ha trasladado a los estudios de género y de la sexualidad, a los estudios postcoloniales y raciales. Ha perdido el formalismo de antańo y ha adquirido una vida nueva y trasplantada en el ámbito de la teoría cultural (BUTLER 9-10).

Es claro que, al margen de estos apuntes, la filiación postestructuralista de Butler la lleva a cuestionar algunos parámetros propios de los feminismos de la igualdad y, en concreto, la manera que tienen estos de entender el género. Para esta labor crítica, Butler participa de lo que se ha denominado, aludiendo a la argumentación nietzscheana, la metafísica de la sustancia, una metafísica que consiste en la operación de hacer de la formulación gramatical entre sujeto y predicado un reflejo de la sustancia y el atributo en un nivel ontológico.

Es decir, para la autora, las concepciones humanistas del sujeto son argumentaciones pilares en los feminismos igualitaristas y universalistas:

Tienen tendencia a dar por sentado que hay una persona sustantiva portadora de diferentes atributos esenciales y no esenciales. Una posición feminista humanista puede sostener que el género es un 'atributo' de un ser humano, caracterizado esencialmente como una sustancia o 'núcleo' anterior al género, denominada 'persona', que designa una capacidad universal para el razonamiento, la deliberación moral o el lenguaje. No obstante, la concepción universal de la persona ha sido sustituida como punto de partida para una teoría social del género por las posturas históricas y antropológicas que consideran al género como una 'relación' entre sujetos socialmente constituidos en contextos concretos (BUTLER 60).

De lo que se trataría, entonces, es de asumir una identidad específica, tanto histórica como políticamente. Y no una identidad fundada (o fundamentada) en algún tipo de entidad natural, primera, auténtica o, a fin de cuentas, precultural. Ya que este no es un momento en que pueda desarrollarse este asunto, tan solo apuntaremos que esta apuesta butleriana es el fruto de sus contribuciones al debate sexo-género. Distinguir sexo y género implica, a juicio de Butler, sostener varias creencias erróneas como, por ejemplo, que el cuerpo es un hecho que nos viene dado. De ahí que nuestra autora sea portadora de una tercera vía transmoderna dispuesta a superar los diversos debates entre modernidad y postmodernidad, igualdad y diferencia y, en definitiva, las dicotomías cuyo sentido es reactualizar lo anterior.

En fin, para proponer a Butler como una autora cercana a una cierta transmodernidad en tanto vislumbra una tercera vía para el feminismo, debemos destacar que este trabajo se adhiere y se reapropia de la definición de transmodernidad que ha presentado Rosa María Rodríguez Magda, sobre todo cuando habla de un 
«abandono de la representación [...] el reino de la simulación, de la simulación que se sabe real» (142), y, también, cuando asevera que la transmodernidad "evidencia una consciencia de la crisis moderna, la insuficiencia de las propuestas postmodernas y la necesidad de un nuevo pensamiento superador que, subterráneamente, marca coincidencias y divergencias» (12).

Desde esta perspectiva, la obra de Butler pretende posibilitar el uso de herramientas conceptuales que sean eficaces para realizar dos ejercicios que, además de estar íntimamente relacionados, resultan pertinentes en nuestra actualidad. En primer lugar, repensar las propuestas liberadoras de la tarea teórico-práctica que desde la modernidad están pendientes. Esto conlleva no desechar apuestas, típicamente modernas, que conviven en el ideal de emancipación. Por ejemplo, el reto (combinado) de alcanzar mayores cotas de libertad individual y ampliar la justicia social. En segundo lugar, reflexionar sobre qué significa hoy la tarea anterior. Es decir, Butler afirma la necesidad de algunas críticas postmodernas en relación con aquellos posicionamientos y situaciones que, de una forma enmascarada, han servido a la imposición de algunos universales y demandas de igualdad. En suma, Butler retoma las riendas de uno de los objetivos fracasados de la modernidad, a saber, la liberación de las personas de aquellas ataduras tradicionales que han pretendido la hegemonía política y social disfrazándose de una naturalidad primera y auténtica. Pero siempre sin escapar de las correcciones imperiosas a las que el pensamiento postmoderno ha dado lugar. Los valores más nobles, esto es, la democracia, la responsabilidad, la justicia, etc., deben adaptarse a la diversidad cultural y a cada situación concreta. $Y$ es que el principio de la diferencia puede ser garante de la dignidad humana en cada caso particular. O sea, ver desde el otro y hacer de la alteridad, expulsada del ensimismamiento europeo, el punto de vista nuclear.

Recibido: el 8 de marzo de 2019; aceptado: el 25 de septiembre de 2019. 


\section{REFERENCIAS BIBLIOGRÁFICAS}

Amorós, Celia. Feminismo y Filosofía. Madrid: Síntesis, 2000.

Amorós, Celia. «Pensar filosóficamente desde el feminismo». Revista Debats, 76 (2002), pp. 66-80.

Butler, Judith. «Imitación e insubordinación de género». Revista de Occidente, 235 (2000), pp. 85-109.

Butler, Judith. Cuerpos que importan. Sobre los limites materiales y discursivos del 'sexo'. Barcelona: Paidós, 2002.

Butler, Judith. El género en disputa. El feminismo y la subversión de la identidad. Barcelona: Paidós, 2007.

Campillo, Neus. «Feminismo, ciudadanía y cultura crítica». Recerca. Revista de pensament i anàlisi, 4 (2004), pp. 167-179.

Cano, Mónica. «Nuevos materialismos: hacia feminismos no dualistas». Oximora. Revista Internacional de Ética y Politica, 7 (2015), pp. 34-47.

Сово, Rosa. «Sexo, demoracia y poder político». Feminismols, 3 (2004), pp. 17-29.

Collın, Françoise. Praxis de la diferencia. Barcelona: Icaria Editorial, 2006.

Femenías, María Luisa. "Postfundacionalismo y contingencia. Butler y el problema del sujeto», en Femenías, María Luisa Femenías y Martínez, Ariel (coords.), Judith Butler: las identidades del sujeto opaco, La Plata: Universidad Nacional de La Plata, 2015, pp. 133-167.

García, Juan A. «La filosofía de la diferencia en la segunda mitad del siglo xx». Thémata, 27 (2001), pp. 201-210.

GarCía, Juan de Dios. «Sujeto y agencia en la teoría política de Judith Butler». Tesis doctoral. Universidad de Sevilla, 2014. URL: https://www.educacion.es/teseo/mostrarRef.do?ref=1110609.

Mayobre, Purificación. «Políticas del tercer milenio: de las viejas luchas a la política de lo simbólico». Riff-Raff. Revista de pensamiento y cultura, 27 (2005), pp. 129-143.

Mayos, Gonçal. «Nietzsche. Pensar más allá de la identidad». Thémata. Revista de Filosofía, 23 (1999), pp. 387-392.

Ortega y Gasset, José. ¿Qué es filosofía? México: Porrúa, 2004.

Pinedo, Javier. «José Ortega y Gasset, España y la modernidad». Cuadernos Americanos, 121 (2007), pp. 41-54.

Reverter, Sonia. «Actos de habla y feminismo», en Casaban, Moya (ed.), Congreso Valenciá de Filosofía, 2002, pp. 167-180.

Reverter, Sonia. «La perspectiva de género en la filosofía». Revista Feminismo/s, 1 (2003), pp. 33-50.

Rodríguez, Rosa María. La sonrisa de Saturno. Hacia una teoría postmoderna. Barcelona: Anthropos, 1989.

Rodríguez, Rosa María. Transmodernidad. Barcelona: Rubí, 2004.

Romero Morales, Yasmina. «La otredad femenina en la narrativa colonial escrita por mujeres: Spivak y los feminismos postcoloniales», en Cuestiones de género: de la igualdad y la diferencia, 12, pp. 39-53

SABSAY, Leticia. «¿En los umbrales del género? Beauvoir, Butler y el feminismo ilustrado». Revista Feminismo/s, 15 (2010), pp. 119-135.

Tarnas, Richard. La pasión en la mente occidental. Girona: Atalanta, 1991. 
